\title{
ENTRE LA REALIDAD Y LA FICCIÓN. EL ORNATO FEMENINO EN LA LITERATURA CASTELLANA BAJOMEDIEVAL Y RENACENTISTA
}

\author{
Adolfo Hamer Flores \\ ahamer@uloyola.es \\ Universidad Loyola Andalucía \\ Teresa María Criado Vega \\ teresa_criado61@yahoo.es \\ Universidad de Córdoba
}

\section{INTRODUCCIÓN}

El objetivo del presente trabajo consistirá en descubrir las descripciones que algunas de las principales obras de literatura castellana no técnica de los siglos XIV a XVI incluyen en sus páginas sobre los afeites femeninos para, posteriormente, compararlas con recetarios técnicos reales ${ }^{1}$. En concreto, emplearemos las recetas recogidas en diversos manuscritos de la Biblioteca Nacional de España ${ }^{2}$ y otro conservado en la Biblioteca Palatina de Parma (Italia) ${ }^{3}$. De este modo, estaremos en disposición de verificar si existen o no similitudes entre ambas realidades, e incluso de afirmar si las obras literarias pudieron ayudar a difundir socialmente procedimientos para realzar la belleza de las mujeres ${ }^{4}$.

\footnotetext{
${ }^{1}$ Pueden verse las características de estos recetarios técnicos en Teresa María Criado Vega, «Las artes de la paz. Técnicas de perfumería y cosmética en recetarios castellanos de los siglos XV y XVI», Anuario de Estudios Medievales, 41/2 (2011), pp. 865-897.

${ }^{2}$ Nos referimos a los manuscritos 1462, 2019, 6058 y 9225.

${ }^{3}$ Es el conocido como Manual de mugeres, incluido en el manuscrito 834 de esta institución.

${ }^{4}$ Sobre el tema que aquí nos ocupa, aunque con un enfoque eminentemente léxico, véase M. ${ }^{a}$ del Pilar Romero del Castillo, Los afeites femeninos en la Edad Media española, Universidad de Granada (Tesis Doctoral inédita), 2013. Del mismo modo, existen una serie de trabajos de obligada lectura para comprender la realidad de la cosmética y la belleza en las mujeres en la etapa medieval y renacentista: Joaquina Albarracín Navarro y Juan Martínez Ruiz, «Farmacopea en La Celestina y en un manuscrito árabe de Ocaña», en Manuel Criado de Val (coord.), La Celestina y su contorno social. Actas del I Congreso Internacional sobre La Celestina, Madrid, Hispam, 1977, pp. 427-432; Ángela Bravo, Femenino singular. La belleza a través de la historia, Madrid, Alianza Editorial, 1996; Montserrat Cabré i Pairet, «Cosmética y perfumería», en Luis García Ballester (ed.), Historia de la técnica y de la ciencia en la Corona de Castilla, Valladolid, Junta de Castilla y León, 2002, vol. II, pp. 773-779; Pedro Correa, «El ideal de belleza femenina en los siglos XII y XIII», en María Isabel Montoya Ramírez (ed.), Moda y sociedad. La indumentaria: estética y poder, Granada, Universidad de Granada, 2002,
} 
Los autores castellanos de los siglos XIV a XVI, unos como medio para criticar a las mujeres -arcipreste de Talavera- y otros para mostrar la vida del momento, no dudaron en recoger en sus escritos $\mathrm{u}$ obras alusiones y descripciones, detalladas y concisas, sobre el uso y el modo de elaborar este o aquel afeite para tener la tez blanca, el cabello dorado, los dientes blancos o los labios de carmín. Así pues, incorporan citas de los cosméticos y sus descripciones varias obras literarias como El Libro del buen amor de Juan Ruiz, arcipreste de Hita; el Llibre de les donnes, de Francesc de Eiximenis, que nos habla del exceso en el vestir, del uso de los cosméticos y del refinamiento en la mesa; el Arcipreste de Talavera o Corbacho, de Alfonso Martínez de Toledo; La Celestina, de Fernando de Rojas; y La Lozana andaluza, de Francisco Delicado.

A la mujer, definida por no pocos autores como ser coqueto y vanidoso, se le exigió desde antaño un canon de belleza que no todas podían alcanzar. Dicho prototipo no siempre fue el mismo, pero sí conocemos el que más perduró en el tiempo y que estuvo vigente a fines del Medievo y principios de la Modernidad. Nos da buena cuenta de éste Juan Ruiz, arcipreste de Hita:

Busca mujer esbelta, de cabeza pequeña, / cabellos amarillos, no teñidos de alheña; / las cejas apartadas, largas, altas, en peña; / ancheta de caderas, esta es talla de dueña. / Ojos grandes, hermosos, expresivos, lucientes / y con largas pestañas, bien claros y rientes; / las orejas pequeñas, delgadas; para mientes / si tiene el cuello alto, así gusta a las gentes. / La nariz afilada, los dientes menudillos, / iguales y muy blancos, un poco apartadillos, / las encías bermejas, los dientes agudillos, / los labios de su boca bermejos, angostillos. / La su boca pequeña, así, de buena guisa, / su cara sea blanca, sin vello, clara y lisa; / conviene que la veas primero sin camisa / pues la forma del cuerpo te dirá: ¡esto aguisa! ${ }^{5}$.

Una descripción a la que también se suma el arcipreste de Talavera al decir que «ella debe tener el cabello dorado o rubio; ojos hermosos; cutis inmaculado, blanco y suave; labios de carmín; cuerpo esbelto $\rangle^{6}$. Otros autores posteriores hacen suyos todos o algunos de dichos elementos, como Garcilaso de la Vega, que incluirá en sus mujeres el tono de cabello dorado y la tez blanca:

pp. 155-186; y Dulce María González Doreste, «Cómo ser bella y no morir en el intento: el ideal de belleza femenino y la cosmetología medieval», en Àngels Carabí y Marta Segarra (eds.), Belleza escrita en femenino, Barcelona, Universitat de Barcelona, 1988, pp. 154-162.

${ }^{5}$ Juan Ruiz, arcipreste de Hita, Libro de Buen Amor, Alberto Blecua (ed.), Madrid, Crítica, 2001, estrofas 432-435.

${ }^{6}$ Alfonso Martínez de Toledo, Arcipreste de Talavera o Corbacho, Michael Gerli (ed.), Madrid, Cátedra, 1979, pp. 39-40. 
Dó están agora aquellos ojos claros / que llevaban tras sí, como colgada, / mi alma doquier que ellos se volvían / ¿Do está la blanca mano delicada, / llena de vencimientos y despojos / que de mí mis sentimientos le ofrecía? / Los cabellos que veían / con gran desprecio el oro, / como a menor tesoro, / ¿A dónde están? ¿A dónde el blanco pecho??

¡Oh claros ojos! ¡Oh cabellos de oro! / ¡Oh cuello de marfil! ¡Oh blanca mano! ${ }^{8}$.

Francisco Delicado, en La Lozana andaluza, recoge también el tono rubio de los cabellos: «Más moza parece que la hija, iy qué cabellos rubios que tenía!'». El color blanco de la tez y del cuerpo son alabados por Fernando de Rojas cuando Calisto, al hablar de Melibea, manifiesta «la tez lisa, lustroza, el cuero suyo escureçe la nieve, la color mezclada, qual ella la escogió para $\left.\mathrm{si}^{10}{ }^{10}\right\rangle$; y también en diversos versos del Cancionero y Romancero español, como aquellos en los que se declama:

Hermosura de mi cuerpo / yo te las hiciera ver: / delgadica en la cintura, / blanca soy como el papel, / la color tengo mezclada como rosa en el rosal, / el cuello tengo de garza, / los ojos de un gavilán, / las téticas agudicas, / que el brial quiere romper, / pues lo que tengo encubierto / maravilla es de lo ver ${ }^{11}$.

Para alcanzar este prototipo o canon de belleza, así como para perpetuar el frescor de juventud, la mujer contó en la época estudiada con una amplia paleta de recursos y con la práctica de un variado elenco de artes dirigidas al logro de estos fines. En esta paleta de afeites ${ }^{12}$ se incluían aderezos ${ }^{13}$ para múltiples destinos: blanquear la piel y los dientes, enrubiar el cabello, cejas finas y arqueadas, encías y labios de color bermejo y depilado de su cuerpo. La descripción de estos potingues fue recogida adoptando el formato de recetas e incorporadas, de una parte, en los llamados Libros de mujeres o Recetarios

\footnotetext{
${ }^{7}$ Garcilaso de la Vega, Poesía castellana completa, Madrid, Ed. Cátedra, 1977, p. 44. Primera Égloga, Nemoroso, vv. 267-276.

${ }^{8}$ Ibidem, p. 50. Segunda Égloga, Albanio, versos 20-21.

${ }^{9}$ Francisco Delicado, La Lozana andaluza, Carla Perugini (ed.), Sevilla, Fundación José Manuel Lara, 2004, p. 43.

${ }^{10}$ Fernando de Rojas, La Celestina, Madrid, Cátedra, 1995, p. 101.

${ }^{11}$ Cancionero y romancero español, Dámaso Alonso (ed.), Madrid, Salvat y Alianza Editorial, 1969, p. 187.

${ }^{12}$ Afeite: aderezo que se pone a alguna cosa para que parezca bien, y particularmente el que las mujeres se ponen en la cara, manos y pechos, para parecer blancas y roxas, aunque sean negras y descoloridas, desmintiendo a la naturaleza y, queriendo salir con lo imposible, se pretenden mudar el pellejo (Francisco de Covarrubias, Tesoro de la lengua castellana o española, Madrid, por Luis Sánchez, 1611; en adelante TLC).

${ }^{13}$ Aderezo: adorno, afeite (TLC).
} 
domésticos -que aquí denominaremos recetarios técnicos- $\mathrm{y}$, de otra parte, en obras de literatura, tanto poesía como prosa.

\section{LAS RECETAS DE BELLEZA EN ALGUNAS OBRAS LITERARIAS MEDIEVALES}

La mujer debía mostrarse siempre bella y, además, debía serlo según el prototipo exigido por la sociedad en cada momento. A fines del Medievo y durante los inicios del Renacimiento (siglo XVI), el canon de belleza exigía, como ya hemos indicado anteriormente, que tuviera los cabellos como hebras de oro, la piel de color blanco, la frente amplia, las cejas finas y arqueadas, el cuerpo esbelto, los dientes blancos y menudos, labios de color carmín y los ojos claros. Un modelo ideal, propio de la mujer nórdica, que era y es poco habitual entre las mujeres del sur de Europa, pues la mujer latina tiene tendencia a la piel algo oscura, el cabello castaño o negro, a un cuerpo no proporcionado y sus ojos suelen ser negros, miel o marrones; en cuanto a sus dientes y labios, sí pueden ser, respectivamente, blancos y menudos, y de color bermejo. El uso de los productos de cosmética hizo posible en aquel entonces que muchas mujeres alcanzaran aquello que la naturaleza les había negado. Se aplicaban sobre la piel, el cabello y la boca, siendo su objetivo, de una parte, mantener la limpieza, la tersura y la flexibilidad de la piel, particularmente del rostro, y de otra, conservar o recobrar el color de la juventud, mantener y blanquear los dientes y hacer desaparecer el mal olor de la boca. Por último, aquellos relativos al cabello perseguían, de un lado, mantenerlo o recuperarlo tanto en su volumen como en su color y, de otro, eliminar el vello superfluo. Estos artículos se muestran bajo formas muy variadas y reciben múltiples denominaciones, tales como esencias, extractos, tinturas, pomadas, cremas, pastas, polvos, ungüentos, depilatorios, aceites o emulsiones. Podían elaborarlos ellas mismas o adquirirlos ya preparados ${ }^{14}$.

Las descripciones de los afeites dirigidos a alcanzar el canon de belleza descrito se encuentran recogidos, como ya hemos comentado anteriormente, tanto en los Recetarios domésticos o Libros de mujeres como en algunas obras literarias, en prosa y en verso. Los ejemplos recogidos, en uno y otro tipo de obras, presentan como veremos a continuación una gran similitud entre ellos, realidad que nos hace pensar que ambas recogen fielmente la realidad del momento. Las obras literarias no parecen fabular o incluir elementos ficticios cuando recogen recetas y técnicas de embellecimiento.

En el siglo XIV, las mujeres castellanas contaban con polvos, afeites y alcoholes, recursos que, en palabras de Juan Ruiz, les proporcionaban las trotaconventos en su deambular, siendo este ofrecimiento,

${ }^{14}$ Teresa María Criado Vega, Tratados y recetarios técnicos medievales, Facultad de Filosofía y Letras, Universidad de Córdoba (Tesis doctoral inédita), 2012. 
en muchas ocasiones, la tapadera de otros servicios menos honestos ${ }^{15}$. Por su parte, el gerundense Francesc de Eiximenis habla de los cosméticos y de su uso comentando, concretamente, que «los rostros de las mujeres se muestran pintados y los ojos alcoholados»; no incluye, empero, descripción alguna de los mismos. Continuando con la crítica de su uso, que es lo que le mueve en su discurso, dice que el acicalamiento en general y ese color que se daban las damas en los rostros, a veces, las hacía irreconocibles ante Dios; una realidad que hacía pensar que la obra de Él fuera imperfecta, lo cual le ofendía. Finalmente, manifiesta que las mujeres aprendían en sus hogares el uso de los afeites y las modificaciones en su exterior, siendo allí donde se observaban y ensayaban ${ }^{16}$. A comienzos de la Edad Moderna, otros autores, como don Pedro de la Cerda y Granada, seguirán manteniendo esa actitud contraria al empleo de los afeites:

De la naturaleza los errores

Que con los ojos a la fea enemista

En remediar que el arte sabia insista

$\mathrm{Su}$ negra noche alegre con colores.

Pase más que la hermosa propias flores

Es mucho con pórtico afeite vista

Porque no la conozca Dios de vista

Que no crió sus falsos resplandores.

Su rostro del gran Juno es vil cautivo

De su boca el tesoro hay ciertas famas

Con mudas que en carbón se le ha mudado.

Lo pintado aunque es sombra de lo vivo

Deste tiempo se ve en diversas damas

En un como lo vivo y lo pintado ${ }^{17}$.

En el siglo xv, las obras sí recogen ya ejemplos de cosméticos descritos con cierta precisión y detallismo. Alfonso de Talavera, en la segunda parte de su obra El Corbacho, denominada «Discurso sobre los vicios, tachas y malas condiciones de las mujeres», hace acopio de un importante número de ejemplos, concretamente, incluidos en los epígrafes tercero ( «Las mujeres aman debido a la gran codicia que albergan») y cuarto («Cómo la mujer es envidiosa de cualquiera más hermosa que ella»). Fernando de Rojas, en La Celestina, habla de los afeites principalmente a través de Pármeno, quien los menciona así al comentar los quehaceres de la Celestina:

\footnotetext{
${ }^{15}$ Ruiz, op. cit., versículo 440.

${ }^{16}$ Francesc Eiximenis, Prosa. Xavier Renedo i Sergi Gascón (eds), Barcelona, Teide, 1993, pp. $135-137$.

${ }^{17}$ Jesús Terrón González, Léxico de cosméticos y afeites en el Siglo de Oro, Salamanca, Universidad de Extremadura, 1990, pp. 26-27. Pedro de la Cerda vivió en el siglo xvII. El texto carece de puntuación.
} 
Hazía solimán, afeyte cosido, $\operatorname{argentadas}^{18}$, bujelladas ${ }^{19}$, cerillas, llanillas $^{20}$, unturillas, lustres, lucentores ${ }^{21}$, clarimentes $^{22}$, alvalines ${ }^{23}$ $\mathrm{y}$ otras aguas de rostro, de rassuras $^{24}$ de gamones $^{25}$, corteza de spantalobos $^{26}$, de taraguntia ${ }^{27}$, de hieles, de agraz, de mosto, destilados y açucarados ${ }^{28}$.

Por último, también Francisco Delicado hizo acopio de un importante número de recetas o descripciones de diversos afeites para hermosearse o cambiar el aspecto las mujeres en su Lozana andaluza ${ }^{29}$.

\footnotetext{
${ }^{18}$ Argentada: especie de afeite que usaban las mujeres para blanquear las manos (Diccionario de la lengua española. Real Academia Española, Madrid, Espasa-Calpe, $22^{\mathrm{a}}$ ed., 2001, 2 vols.; en adelante DRAE).

${ }^{19}$ Bujelada: cierta especie de agua compuesta para blanquear y labrarse el rostro (DA, Tomo V, Año 1737) / Antiguamente afeite para el rostro (DRAE).

${ }^{20}$ Llanilla: Afeite para allanar asperezas (Terrón González, op. cit., p. 149). Tipo de afeite que usaban las mujeres antiguamente (DRAE).

${ }^{21}$ Lucentor: cierto afeite que usaban las mujeres para el rostro (DRAE).

${ }^{22}$ Clarimente: agua compuesta o afeite que usaban las mujeres para lavarse el rostro y componerlo (Diccionario de la lengua castellana en que se explica el verdadero sentido de las voces, su naturaleza y calidad con las phrases o modos de hablar, los proverbios o refranes y otras cosas convenientes al uso de la lengua, Madrid, Imprenta de Francisco del Hierro-Imprenta de la Real Academia Española, 1726-1739, 6 vols., en adelante DA; tomo II, año 1729).

${ }^{23}$ Albalino: afeite que usaban antiguamente las mujeres para blanquearse el rostro (Terrón González, op. cit., p. 55).

${ }^{24}$ Rasuras: en plural se llaman así las heces del vino, que sirven en cocimiento para blanquear la plata y para otros usos (DA, tomo V, año 1737).

${ }^{25}$ Nombre frecuente en toda España para designar las especies del género Asphodelus (Manuel Pardo de Santayana, Estudios etnobotánicos en Campóo (Cantabria): conocimiento y uso tradicional de plantas, Madrid, CSIC, 2008, p. 67).

${ }^{26}$ Árbol pequeño, o especie de arbusto, cuyas hojas son mui semejantes a las de la Sena, y produce unas vainillas, y dentro de ellas una simiente como la Lenteja. Los hollejos de las vainillas son tan hinchados y llenos de viento, que en apretándolos entre los dedos, revientan y dan grande estallido. Llámese Espantalobos por el estruendo que hacen los hollejos agitados del viento. Latín. Colutea. LAG. Diosc. lib. 3. cap. 79. Llámese la Colutea en Castilla Espantalobos por el grande ruido que hacen sus hollejos, cuando movidos del viento se tocan unos con otros (DA, tomo III, año 1732).

${ }^{27}$ Taraguncia: taragontía (Dragontea o Serpentaria: hierba de que hay dos especies mayor y menor. La mayor produce un tallo derecho, liso, largo de dos codos, del grueso de un cordón, de color vario y diferenciado con ciertas manchas purpúreas, de suerte que parece serpiente. Las hojas son como las de la Romaza, envueltas unas en otras. Al fin del tallo sale una hoja encogida y cerrada, ancha por el pie, y por lo alto mui puntiaguda, la cual por fuera es verde, y por dentro teñida de un rojo oscuro. Se abre con el tiempo, y descubre en medio una como lengua bermeja, semejante a un cuerno de cabra, al pie del cual nace su fruto, que al principio es pardillo, y una vez madurando se vuelve del color de azafrán subido. La raíz es de mediana grandeza, redonda, blanca, y vestida de una cubierta o corteza sutil. La menor produce diferentes tallos, al fin de los cuales nacen unas hojas como las de la Hiedra grandes y diferenciadas con ciertas señales blancas. La raíz es algo redonda, cebolluda y semejante al Ajo. Llámese también Taracontena mayor y menor. Latín. Dracontium, ii. Apud officinas, Serpentaria, et columbina. LAG. Diosc. lib. 2. cap. 156. Es la dragontea mui aguda y amarga con grande sutileza de partes; aunque tiene alguna estipticidad. Se usa en la elaboración de ungüentos (DA, tomo III, año 1732).

${ }^{28}$ Fernando de Rojas, op. cit., p. 111.

${ }^{29}$ Delicado, op. cit., pp. 41, 84, 216 y 316-317.
} 


\subsection{Cuidado de la piel: manos y rostro}

Los afeites o cosméticos que cuidan de las manos y rostro se presentan bajo distintas formas: cremas o untos ${ }^{30}$, mudas ${ }^{31}$, aceites $\mathrm{u}$ óleos y aguas. El factor o elemento que marca la diferencia entre unas recetas y otras son las materias que participan y no el tratamiento que se sigue hasta su elaboración. Las materias primas se adscriben especialmente a tres modalidades: grasas (vegetales y animales), sustancias aromáticas y aguas de olor. En las recetas pueden aparecer un mayor o menor número de sustancias, así en los ejemplos recogidos en los recetarios castellanos suelen incluirse un elevado número mientras que los casos que aparecen en las obras de literatura se caracterizan por incluir un reducido número de sustancias y apenas detallan el proceso de elaboración.

En la obra del arcipreste de Talavera estos se localizan concretamente en su segunda parte, epígrafe tercero, y se dirigen, a las manos y lo hacen bajo las formas de jabón para el rostro, aguas, cremas y óleos; y en La Celestina se las debemos preferentemente a Pármeno, estando destinadas a la cara y sus modalidades son las mismas: crema, unto y óleo. Por último, en La Lozana andaluza son para la piel, en general, y la cara, en particular, cerillas, mudas y solimán.

\subsubsection{Jabón de rostro}

Se trata de un tipo de jabón distinto al que se emplea para hacer la colada o para el mundo de la industria de tinte. De él nos trae un ejemplo el arcipreste de Talavera, en el que parte de un jabón ya elaborado, jabón napolitano, al que se unen almizcle, algalia, clavo de giroflé remojado previamente en agua o flor de azahar, y dice así: «Al jabón obtenido se le añade almizcle, algalia, clavos de giroflé, todo remojado durante dos días en agua de azahar o en flor de azahar» ${ }^{32}$.

En los recetarios técnicos hemos localizado una receta con bastantes coincidencias con la anterior y que dice así: «una vez elaborado del jabón napolitano añade almizcle, algalia, clavos de giroflé, remojados dos días en agua de azahar o flor de azahar, mezclado con ello y se hará un rico jabón napolitano, y con esto tendrán las manos blandas como la seda» ${ }^{33}$; así como otra con algunas variantes, pues al jabón se le agregan frutos secos molidos y aceite de adormidera ${ }^{34}$.

\footnotetext{
${ }^{30}$ Unto: ungüento (DRAE). Cualquier graso, como unto de puerco (TLC).

${ }^{31}$ Muda: cierta untura que las mujeres se ponen en la cara para quitar de ellas las manchas (TLC).

${ }^{32}$ Martínez de Toledo, op. cit., p. 158.

${ }^{33}$ Biblioteca Nacional de España -en adelante BNE-, ms. 9226, p. 59: «Jabón blanco napolitano».

${ }^{34}$ BNE, ms. 2019, f. 43v: «Xabón de rostro». Biblioteca Palatina de Parma -en adelante BPP-, ms. 834, f. 2: «Jabón para el rostro».
} 


\subsubsection{Ungüento o unto}

El siguiente cosmético o afeite es el ungüento, potingue que se obtiene tras mezclar perfectamente grasa, sustancias aromáticas y aguas de olor. El proceso de fabricación se suele iniciar incluyendo la grasa, incorporación que puede hacerse mediando cocción o simplemente batiéndola, tras lo cual se añadirían las materias olorosas. En La Celestina, Pármeno menciona este afeite y lo hace usando el término «unto», aunque se limita a indicar el animal del que puede proceder la grasa: «los untos para el rostro se hacen con grasa de vaca, oso, caballo, camello, culebra, conejo, ballena, garza, alcaraván, gamo, gato montés, tejón, harda ${ }^{35}$, erizo y nutria $\aleph^{36}$. Por su parte, en La Lozana andaluza, al hablar del afeite se mencionan los ingredientes y se especifica el fin: «la manteca de cerdo, aromatizado con espliego, servía para blanquear la piel $\diamond^{37}$.

En el total de ejemplos localizados de este cosmético entre las recetas técnicas ${ }^{38}$, aparecen los tres tipos de ingredientes citados: grasas, animales, vegetales y aceites; así como sustancias olorosas y aguas de olor, a las que se unen, según los casos, cítricos, solimán, blanquete, espuma de cera, almaciga o almástiga, trementina, clavo de giroflé y manzana dulce.

\subsubsection{Mudas}

Otro cosmético son las mudas ${ }^{39}$, artículo recomendado en $\mathrm{La} \mathrm{Lo}$ zana andaluza al indicar que "se dan las mujeres todas las noches en la cara [con ellas], que si se dejan de poner, no vale para nada $»^{40}$. También son citadas junto con otros afeites por el autor toledano del siglo xv Rodrigo Cota en su obra Diálogos entre el amor y un viejo:

\footnotetext{
${ }^{35}$ Harda: ardilla.

${ }^{36}$ Según Pármeno, los untos para el rostro se elaboraban con estos ingredientes (Rojas, op. cit., p. 39).

${ }^{37}$ Delicado, op. cit., p. 35.

${ }^{38}$ Recetas de ungüentos: BNE, ms. 6058, f. 180v: «Receta de un ungüento utilísimo» y BPP, ms. 834, f. 27r: «Receuta para hacer ungüento çetrino» (Alicia Martínez Crespo (ed.), Manual de Mugeres en el qual se contienen muchas y deversasreçeutas muy buenas, Salamanca, Universidad de Salamanca, 1995, pp. 52-53). Recetas de blanduras para las manos: BPP, ms. 834, f. 9v: «Blanduras para las manos» (Manual de Mugeres en el qual se contienen muchas y deversas reçeutas muy buenas, Alicia Martínez Crespo (ed.), Salamanca, Universidad de Salamanca, 1995, pp. 53-53). Recetas de sebos: BNE, ms. 1462, f. 18v: «Como se hace el sebo de manos de solo cabrito» y BPP, ms. 834, f. 25r: «Sevo para las manos» (Martínez Crespo, 1995, pp. 52-53). Recetas de blanduras para las manos: BPP. ms. 834, f. 9v: «Blanduras para las manos» (Martínez Crespo, op. cit., pp. 52-53). Blanduras para el rostro: BPP, ms. 834, f. 20r: «La blandura para el rostro» (Martínez Crespo, op. cit., p. 66).

${ }^{39}$ Muda: cierta untura que las mujeres se ponen en la cara para quitar de ella las manchas (TLC).

${ }^{40}$ Delicado, op. cit., p. 35.
} 
Yo hallo las argentadas / yo las mudas y cerillas, / lucentoras, unturillas, / y las aguas estiladas), y quitar cejas y afeitar novias y hacer mudas de azúcar cande y agua de azofeifas, y alguna vez apretaduras $^{41}$.

Las mudas constan de zumo (de raíces de lirio cárdeno, de uva, de hojas de rábano...), jabón, hiel de vaca, aceite (de pepitas o de adormideras, de almendras amargas, de mata...), cardenillo, azogue muerto y jibia. El arcipreste de Talavera recoge tres ejemplos en su libro para la cara: la primera, zumo de hojas de rábano, azúcar y jabón de Chipre; la segunda, aceite de almendras, habas que sean cochas con la hiel de la vaca; y la tercera, aceite de almendras, habas que sean cochas con la hiel de la vaca, tuétano, pie de carnero negro y cera blanca ${ }^{42}$. Finalmente, La Lozana andaluza, además de recomendar su uso siguiendo el ejemplo de las damas, ofrece una descripción en torno a su elaboración, descripción, por cierto, muy concisa y distinta a la ofrecida por Alfonso Martínez de Toledo: «mezclen óleo de pepitas de calabaza y agua de flor de haba a la veneciana $\rangle^{43}$.

En las recetas técnicas castellanas, localizamos un ejemplo que recoge varios de los ingredientes que veíamos enumerados en los ejemplos que nos ofrece el arcipreste de Talavera; concretamente, habas, azúcar, jabón y zumo de rábano. No incluye las grasas, vegetales o animales. La receta castellana incorpora los altramuces, la negrilla, el blanco de huevo y el atincar, y dice así:

Toma una escudilla de habas blancas, otro tanto de frencos de garbanzos negros tirada la corteza, otro tanto de altramuces, otro de negrilla y otro tanto de simiente de rábanos. Todo esto sea molido y amasado con zumo de rábanos de lo blanco, enjugarlo a la sombra y tornarlo a moler, amasarlo con lo blanco del huevo, y desque sea seco molerlo y cernirlo por cedazo espeso. Después tomad una onza de atincar, media de azúcar cande y una de jabón; y todo sea molido y cernido, y vuelto con la otra pólvora ${ }^{44}$.

Otro recetario castellano incorpora una receta que incluye entre sus ingredientes el óleo de pepitas de calabaza, un elemento que Francisco Delicado mencionaba en su texto.

Toma una cuarta de aceite de pepitas de calabaza, de adormideras y almendras amargas, partes iguales, y un poco de unto de anadón. Si fuere el unto añejo se lavara con agua cinco o seis veces. Sea todo

${ }^{41}$ Fernando de Rojas, Tragicomedia de Calisto y Melibea. V Centenario: 1499-1999. Fernando Cantalapiedra Erostarbe (ed.), Kassel, Reichenberger, 2000, p. 1576.

${ }^{42}$ Martínez de Toledo, op. cit., pp. 162-163.

${ }^{43}$ Delicado, op. cit., p. 84.

${ }^{44}$ BNE, ms. 2019, f. 157r: «Harina para lavar el rostro». 
cocido con su cera de hojuela, después échalo en un vaso con agua rosada y confínese. Primero se ha de lavar con agua dulce ${ }^{45}$.

También en el Manual de mugeres ${ }^{46}$ se incluyen dos recetas que mencionan varias materias incluidas en El Corbacho. Nos referimos al zumo, que en las recetas técnicas es de raíces de lirio cárdeno o de uva, mientras que en la obra literaria es de hojas de rábano; al jabón, francés en las primeras frente al de Chipre que incluye en la segunda; y la hiel de vaca y aceite de almendras. Las recetas castellanas añaden, además, aceites (de adormidera y de mata), cardenillo, azogue muerto y jibia.

\subsection{4. Óleo o aceite}

El óleo o aceite se caracteriza por incorporar grasa de origen vegetal. En el ejemplo que recoge el arcipreste de Talavera, se usa de dos tipos: de pepitas y de alholvas; uniéndoseles simiente de nies$\mathrm{pla}^{47}$. La Celestina también incluye un ejemplo, que aunque no mencione específicamente el aceite, entre los ingredientes es fácil que uno o varios tuvieran forma de aceite:

El óleo para la cara se elabora a base de estoraque, jazmín, limón, pepitas, violetas, benjuí, alfócigos ${ }^{48}$, piñones, granillos, azofeifas ${ }^{49}$, neguilla ${ }^{50}$, altramuces, arvejas ${ }^{51}$, carillas ${ }^{52}$, hierba pajarera ${ }^{53}$ y limón $^{54}$.

En el Manual de mugeres, recetario técnico castellano, se incorporó una receta de este tipo ${ }^{55}$; un ejemplo que, como en el caso de $L a$ Lozana andaluza, no parece que incluya aceite. Ahora bien, éste muy bien podría haber sido sustituido por otro elemento: engrudo. Además de éste último, también se mencionan aguardiente, ceniza fría,

\footnotetext{
${ }^{45}$ BNE, ms. 2019, f. 238r: «Para hacer blanduras».

${ }^{46}$ BPP, ms. 834, ff. 11v-12r: «Mudas para las manos» y f. $39 \mathrm{r}$ y v: «Mudas parar las manos» (Martínez Crespo, op. cit., pp. 66 y 87).

${ }^{47}$ Niespla: nísperos.

${ }^{48}$ Alfócigo: alfóncigo (árbol del que se obtiene el pistacho, así como la resina conocida como almáciga, concretamente del tronco y de las ramas, DRAE).

${ }^{49}$ Azofeifa: azufaifa (fruto del azufaifo. Es una drupa dulce y comestible, que se empleaba como medicamento pectoral, DRAE).

${ }^{50}$ Neguilla: ajenuz o arañuelo (planta que se cría hortense y silvestre, que produce unos ramos sutiles y largos de dos palmos, las hojas pequeñas y menudas: echa en lo alto una cabecilla pequeña, larga [i.116] y sutil como la de las adormideras, dentro de la cual se encierra una simiente negra olorosa, y aguda al gusto, que ordinariamente se echa en el pan cuando se amasa (DA, tomo I, año 1726).

${ }^{51}$ Arveja: legumbre similar a la haba (DA, tomo I, año 1726).

${ }^{52}$ Carilla: fruto parecido a la judía (DRAE).

${ }^{53}$ Hierba pajarera: álsine u oreja de ratón (DA, tomo I, año 1726).

${ }^{54}$ Delicado, op. cit., p. 195.

${ }^{55}$ BPP, ms. 834, f. 3r: «Azeite para tener frescas las caras» (Martínez Crespo, op. cit., p. 42).
} 
borra (pelo de los mamíferos con aspecto lanoso); elementos todos ellos que no se recogen en ninguna de las obras literarias analizadas.

\subsubsection{Aguas para el rostro}

Como colofón del cuidado de la piel, manos y rostro encontramos las aguas. El Corbacho recoge dos ejemplos: uno de ellos, encaminado a estirar el cuero de las manos y senos, incluye el azogue ${ }^{56}$; mientras que el otro, destinado a ablandar y purificar las manos y la cara, presenta entre sus ingredientes huevo, trementina y bórax, dice así: «se toma clara de huevo, destilada con mirra, canfora, angelo$\mathrm{res}^{57}$, trementina -con tres aguas purificadas e bien lavadas, que torne como la nieve blanca-, añada raíces de lirio blanco y bórax fino» ${ }^{58}$. Fernando de Rojas, por su parte, afirma en La Celestina que las aguas para el rostro se pueden elaborar «de rasuras, gamones, corteza de espantalobos, taraguncia, hieles, agraza, mosto, ellas destiladas y

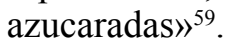

Dos son las recetas técnicas castellanas que describen este cosmético. Entre sus ingredientes incluyen al argento vivo sublimado, mirra, huevos y trementina, sustancias presentes en los ejemplos anteriores; a los que se suman, en un caso, azúcar, leche de cabra, vino tinto clarete y grasa de pato ${ }^{60} \mathrm{y}$, en otro, azucena, alquitira, alcanfor, adormidera, incienso y clarimente ${ }^{61}$.

Finalmente, para el cuidado del rostro la obra de Fernando de Rojas también recomienda el uso de mosto, un ingrediente al que si se añadía un poco de membrillo daba lugar a un excelente jarabe para tomar ${ }^{62}$.

\subsection{Cuidado de las axilas y cejas}

En cuanto al cuidado de las cejas encontramos dos realidades diferentes: de un lado, la eliminación del mal olor, cuestión recogida en El Corbacho, y de otro, la depilación. La desodorización abarcaba las cejas y las axilas, aromatizados con una mezcla resultante de algalia más almizcle ${ }^{63}$. Para la depilación, es decir, para tener las cejas bien peladas, altas y puestas en arco y la frente ancha, las mujeres contaban con un amplio abanico de opciones, destacando entre

\footnotetext{
${ }^{56}$ Martínez de Toledo, op. cit., p. 58.

${ }^{57}$ Angelores: conocida bajos los nombres de Anglores, Sarcocola, Angelote, Azarote, es una especie de goma (Rudín, op. cit., p. 119).

${ }^{58}$ Martínez de Toledo, op. cit., pp. 158-159.

${ }^{59}$ Según Pármeno, el agua para el rostro se elaboraba con estos ingredientes (Rojas, op. cit., 1969, p. 39).

${ }^{60}$ BPP, ms. 834, f. 13r: «Aguas para lavar el rostro» (Martínez Crespo, op. cit., p. 57).

${ }^{61} \mathrm{BNE}$, ms. 1462, f. 20v: «Memoria de agua para aclarar el rostro, muy buena».

${ }^{62}$ Delicado, op. cit., p. 216.

${ }^{63}$ Martínez de Toledo, op. cit., p. 159.
} 
ellas la presencia de resinas y sustancias cáusticas como el sulfuro arsénico o la cal viva. Asimismo, también se recurría a la depilación con pinzas, al uso de agujas calientes clavadas en el bulbo piloso ${ }^{64} \mathrm{e}$ incluso tiras de tela impregnadas de resina ${ }^{65}$.

Las obras literarias consultadas indican que debía usarse para la depilación una mezcla de pez, trementina y aceite de manzanilla ${ }^{66}$, pudiendo incorporar además calcina ${ }^{67}$ virgen y de cera ${ }^{68}$. Fernando de Rojas nos dice a través de Calisto que las mujeres «pelan sus cejas con tenacicas y pegones ${ }^{69}$ y Francisco Delicado nos detalla hasta cuatro procedimientos diferentes en La Lozana andaluza: utilizar la atanquía ${ }^{70}$, aplicar un vidrio sutil ${ }^{71}$, emplear un pelador o escoriador ${ }^{72}$ y usar barboquejos y jáquimas ${ }^{73}$.

Las recetas técnicas castellanas, por su parte, distinguen dos realidades: los depilatorios y aquellos compuestos que tratan de evitar, de un lado, que resurja el vello donde se quitó, y de otro, que aparezca. Respecto al primer caso, depilatorios, las recetas castellanas muestran que el vello se podía eliminar con la ayuda de tiras de tela impregnadas de resinas o destruyendo los bulbos con agujas al rojo. Para ensanchar la frente, concretamente, se usaban unas mudas constituidas por un preparado que solía elaborarse mezclándose perfectamente jabón, algún disolvente (trementina, hiel y yema de huevo), acetatos (cardenillos, agrio de limón y agraz), grasa animal y vegetal (de almendras, lentisco o pepitas), adormideras, azogue y zumo de raíces de lirio cárdeno ${ }^{74}$. A esta modalidad podrían adscribirse los ejemplos recogidos por los autores antes mencionados. Otro elemento que recogen las recetas es el pelador, cuyos ingredientes más comunes eran resinas y agua, seguidas de cera nueva ${ }^{75}$, un cosmético que no aparece recogido por ninguno de nuestros autores literarios, así como tampoco se hacen eco de los compuestos que, según sus defensores, impedirían que volviera a salir el vello ${ }^{76} \mathrm{o}$ aquellos otros que no dejarían que naciera ${ }^{77}$.

${ }^{64}$ Dominique Barthélemy, Historia de la vida privada. De la Europa feudal al Renacimiento, 2 vols., Madrid, Taurus, 1988, vol. 2, p. 359.

${ }^{65}$ Ídem, p. 591. BPP, ms. 834, fol. 11v y BNE, ms. 6058, f. 166r.

${ }^{66}$ Martínez de Toledo, op. cit., pp. 162-163. Delicado, op. cit., p. 84.

${ }^{67}$ Calcina: mezcla de cal, piedra menuda y otros materiales (DA, tomo II, año 1729).

${ }^{68}$ Delicado, op. cit., p. 84.

${ }^{69}$ Rojas, op. cit., pp. 85-86.

${ }^{70}$ Atanquía: cierta goma o betún o ungüento que hecho emplasto y puesto sobre el cuero, arranca los pelos, vulgarmente se le conoce como cerote / Era un ungüento depilatorio, entre sus ingredientes se encontraba la cal viva o calcina, aceite y otras cosas (Delicado, op. cit., p. 100).

${ }^{71}$ Ibidem, p. 84.

${ }^{72}$ Terrón González, op. cit., p. 171.

${ }^{73}$ Delicado, op. cit., p. 347. Jáquima: emplasto depilatorio que se hace con pez u otra cosa pegajosa (Terrón González, op. cit., p. 137).

${ }^{74}$ BPP, ms. 834, f.11 y BNE, ms. 6058, f. 166r.

${ }^{75}$ BPP, ms. 834, f. 11r: «Pelador para el vello» (Martínez Crespo, op. cit., p. 55).

${ }^{76}$ BPP, ms. 834, f. 25v: «Para quitar el vello que no vuelva» (Martínez Crespo, op. cit., p. 74).

${ }^{77}$ BNE, ms. 6058, f. 164v: «Recepta para que no nazca el cabello donde se caiga». 


\subsection{Cuidado de la boca: dientes y labios}

Otra parte del cuerpo a la que desde siempre el hombre ha prestado gran atención ha sido la boca, centrándose en su olor, el blanqueado de los dientes y el buen estado de los labios. Respecto a cómo mantener blanco el esmalte de los dientes y evitar la halitosis o mal olor, don Alonso de Chirinos, médico personal de don Juan II de Castilla y fuente de inspiración de las recomendaciones recogidas en $L a$ Lozana andaluza, afirmaría que "para limpiar los dientes, aconseja el agua fría, y para combatir la halitosis recomendaba compuestos de mirabolanos, junco, corteza de naranja y almástiga ${ }^{78}$. Alfonso Martínez de Toledo indicaría que no había mejor remedio para los dientes que emplear cera, debiendo lavarlos con agua fría y mascar almáciga y limpiárselos con raíces de malvas cochas en vino ${ }^{79}$.

En El Corbacho se indica que para evitar el mal olor de boca «mezcle perfectamente cinamomo y clavos de giroflé, y una hez hecho laven con ello la boca» ${ }^{80}$, $y$ «para los dientes anocegados o fregados con mambre, yerba que llaman de India $»^{81}$.

El cuidado de los dientes es el objeto principal de las recetas técnicas que hemos localizado vinculadas al cuidado de la boca. Se refieren principalmente a la limpieza, blanqueamiento, afirmación y encarnación, siendo escasa, a diferencia de lo que nos muestra la literatura, la preocupación por la halitosis. También están presentes ingredientes como el vino ${ }^{82}$, la almástiga ${ }^{83}$, los clavos de giroflé ${ }^{84} \mathrm{y}$ la cáscara de naranja ${ }^{85}$; aunque observamos que hay dos grandes grupos de remedios. De un lado, ejemplos muy sencillos y asequibles para el conjunto de la sociedad y, de otro, recetas más completas y con componentes que estaban al alcance de unos pocos. Entre los primeros sobresale el uso de agua destilada de limón o el propio zumo de éste ${ }^{86}$; mientras que las segundas incluyen sustancias tan exclusivas como alabastro, perlas o aljófar, mirra, sangre de dragón, coral (rosado y blanco), almizcle, ámbar, algalia, flor de carrasca o raíces de violeta o en su defecto raíz de lirio. Veamos una de estas últimas:

Primeramente tomará aljófar peso de tres reales, mirra peso de otros tres, sangre de drago de gota otras tres, coral colorado y preparado

\footnotetext{
${ }^{78}$ Delicado, op. cit., p. 316. Se cita la obra Menor daño de medicina de A. de Chirinos.

${ }^{79}$ Ibidem, pp. 316-317.

${ }^{80}$ Martínez de Toledo, op. cit., p. 159.

${ }^{81}$ Ibidem, pp. 162-163.

${ }^{82}$ BNE, ms. 9226, pp. 89-90: «Lavatorio para los dientes».

${ }^{83} \mathrm{BNE}, \mathrm{ms} .2019$, f. 17v: «Recepta para hacer agua para los dientes»; f. 43r: «Para encarnar, confirmar y emblanquecer y hacer coloradas las encías»; y ff.84v-85r: «Polvos para los dientes».

${ }^{84}$ BNE, ms. 2019, f. 28r: «Agua para los dientes»; ff. 84v-85r: «Polvos para los dientes»; y f. 210r: «Memorias de polvos para los dientes».

${ }^{85}$ BNE, ms. 2019, f. 210r: «Memorias de polvos para los dientes».

${ }^{86} \mathrm{BNE}$, ms. 9226, p. 88: «Para parar blancos los dientes».
} 
otras tres, y coral blanco peso de real y medio. Y deshacerlo bien y de esta manera lo ha de hacer nueve veces y después de haberlo hecho molerá el almizcle, y si pone un poco de ámbar y un poco de algalia será mejor, y si no se halla flor de carrasca las raíces de las violas boscanas pueden ser en su lugar, y si no se halla las raíces puedense hacer con la raíz del lirio azul al tiempo que por quien el almizcle ha de picar un grano de grano en grano ${ }^{87}$.

Para concluir con el cuidado u ornato de la boca, el canon de belleza imponía a las mujeres que sus labios debían mostrarse de color rojo carmín y para ello dispusieron de cosméticos cuyas descripciones también fueron recogidas en la literatura; no así en los recetarios técnicos, donde no nos ha sido posible localizarlos. El arcipreste de Talavera menciona el siguiente ejemplo: «para los besos muy bermejos, se emplea pie de palomina grana, mezclado con brasil y alumbre ${ }^{88}$.

\subsection{Para enrubiar los cabellos}

Una última cuestión, aunque no por ello de menor interés, fue el deseo de toda mujer por tener unos cabellos tan rubios como las hebras de oro. Para tal fin, disponían de una lejía distinta de la empleada para elaborar el jabón, conocida como lejía para enrubiar y que se elaboraba con ceniza de sarmiento y vino blanco. De la importancia de esta práctica dan buena cuenta las numerosas referencias incluidas en las obras literarias. En La Celestina, Pármeno, como en otros casos, nos descubre que la señora Trotaconventos para dar ese color a los cabellos de sus clientes, «hace lejía para enrubiar con ceniza de sarmientos, carrasca, centeno o de marrubios; más salitre, alumbre, millefolia ${ }^{89}$, y otras cosas más». Calisto, por su parte, afirma: «buscan las doradas hierbas, raíces y flores para hacer lejías, con que sus cabellos semejasen a los de ella [Melibea] $\gg{ }^{90}$. Por su parte, en La Lozana andaluza se afirma que para el teñido del cabello se emplea la alheña ${ }^{91}$, como lo prueba este fragmento: «¿De qué, señora? Sé hacer alheña y mudas, y tez de cara, que aprendí en Levante sin lo que mi madre me mostró» ${ }^{92}$.

${ }^{87}$ BNE, ms. 2019, ff. 34v-35r: «Recepta para afirmar los dientes y para ponerlos blancos de la señora condesa de Lerma».

${ }^{88}$ Martínez de Toledo, op. cit., pp. 162-163.

${ }^{89}$ Milefolia, Millifolia o Milefolium: plantita rastrera parecida al hinojo naciente (J. Corominas y J.A. Pascual, Diccionario etimológico castellano e hispánico, Madrid, Ed. Gredos, 1983).

${ }^{90}$ Rojas, op. cit., pp. 34 y 39.

${ }^{91}$ En El Tesoro de la Lengua Castellana de Sebastián de Covarrubias, y entre las anotaciones que hizo Laguna a la obra de Dioscórides, se señala que con las raíces de este arbusto, ligustro, solían teñir en Turquía las colas y crines de los caballos (Delicado, op. cit., p. 41).

92 Terrón González, op. cit., p. 57. 
Los recetarios técnicos castellanos también se hacen eco de esta práctica de belleza, concretamente en una receta recogida en el Libro de mugeres ${ }^{93}$. En ella, al igual que manifestara Pármeno, encontramos cenizas de sarmiento, a las que se unen en este caso raíces de hiedra o de olmo, más jabón francés, agua de lluvia, regaliz o cúrcuma y bórax de vino blanco o nitro blanco.

\section{CONCLUSIONES}

Como conclusión del presente trabajo, podemos afirmar que la cosmética, arte que desde antaño viene acompañando al hombre y es capaz de crear una imagen ficticia - pero próxima al modelo o canon de belleza del momento- de una persona ante los demás, se preocupaba y preocupa por realzar los principales rasgos del rostro, ojos y boca, así como por lograr una piel cuidada y con el tono de moda, limpia de toda mancha y vello superfluo. Del mismo modo, puso atención especial en el cabello, buscando, en la época que aquí hemos analizado, que su color fuese rubio. Unos objetivos que podían ser alcanzados en la época Bajomedieval y los inicios del Renacimiento mediante el empleo de una considerable y variada gama de afeites, ungüentos, mudas, aceites, aguas y tintes. Ciertamente, su uso contó con no pocos detractores, procedentes fundamentalmente de los sectores eclesiásticos, pero no por ello dejaron de ser habituales y de empleo generalizado.

Varias obras de la literatura castellana medieval y de principios del siglo XVI, concretamente algunas de las más conocidas como La Celestina, El Corbacho o La Lozana andaluza, recogieron entre sus páginas el uso de estos cosméticos, y aunque no indicaron casi nada acerca de su elaboración sí que anotaron los ingredientes. Unas descripciones que en las diferentes tipologías analizadas en los apartados anteriores muestran claramente una considerable similitud con los recetarios técnicos castellanos coetáneos, permitiéndonos sostener que las referencias incluidas en la literatura plasmaron conocimientos reales de su época. De este modo, las informaciones sobre procedimientos y recetas de belleza que hemos localizado y analizado en esas obras de ficción, vienen a sumarse como una fuente más para conocer mejor el ornato femenino en la Baja Edad Media y comienzos de la Modernidad.

${ }^{93}$ BPP, ms. 834, f. 23r: «Lejía para enrubiar» (Martínez Crespo, op. cit., pp. 70-71). 
$\cos$

ENTRE LA REALIDAD Y LA FICCIÓN. EL ORNATO FEMENINO EN LA LITERATURA CASTELLANA BAJOMEDIEVAL Y RENACENTISTA

RESUMEN: El presente trabajo analiza las técnicas de elaboración de cosméticos contenidos en obras de literatura castellana de fines del medievo y primeros momentos del Renacimiento, comparándolas con la realidad recogida en recetarios castellanos coetáneos. En dichas obras aparecen un número importante de recetas que muestran el fin de los afeites, los ingredientes usados en su elaboración y, en menor medida, el proceso o procesos seguidos en su ejecución. Todo ello pone de relieve una faceta poco estudiada de la vida cotidiana del medievo y primeros años del Renacimiento, relacionada con la estética y la belleza y con el cuidado del cuerpo.

Palabras clave: canon de belleza, cosmética, literatura castellana, recetas, mujer.

\section{BETWEEN REALITY AND FICTION. FEMALE ORNAMENT IN LATE MEDIEVAL AND RENAISSANCE SPANISH LITERATURE}

ABSTRACT: This paper analyzes the techniques for preparing cosmetic contained in works of Spanish literature of the late Middle Ages and early Renaissance times, comparing with reality recipe collection in Castilian contemporaries. In such work a number of recipes to show the makeup, the ingredients used in its preparation and to a lesser extent, the process or processes used in its execution appear. All this highlights a little-studied facet of daily life in the Middle Ages and early Renaissance, related to aesthetics and beauty and body care.

KEYwORDS: canon of beauty, cosmetics, Spanish literature, recipes, woman. 